\title{
Quantitative Determination of Menthol in a Single Puff of Mainstream Cigarette Smoke*
}

\author{
by \\ Narendra K. Meruva, Matthew T. Smith, and Susan E. Plunkett \\ Altria Client Services, Research Development \& Engineering, 601 E. Jackson Street, Richmond, VA-23219, USA
}

\section{SUMMARY}

A method for the determination of menthol in a single puff of mainstream cigarette smoke is reported. A rotary smoking machine with a twin filter interface was used to smoke cigarettes with varying menthol and "tar" deliveries determined based on the Cambridge filter method. The twin filter interface mechanically switches to a new filter pad for collection of smoke from each cigarette puff. The individual filter pad extracts were analyzed by gas chromatography-mass spectrometry (GC-MS) to determine menthol puff-by-puff deliveries. Menthol puff-by-puff profiles show an increase in menthol smoke delivery with increasing puff count, a trend consistent with total particulate matter and smoke delivery profiles of other mainstream smoke constituents. The sum of single puff menthol deliveries is comparable to the whole cigarette menthol smoke delivery as collected on a single filter pad. This method can also determine quantitative puff-by-puff deliveries of other mainstream cigarette smoke constituents. [Beitr. Tabakforsch. Int. 25 (2013) 528-534]

\section{ZUSAMMENFASSUNG}

Es wird eine Methode zur Bestimmung von Menthol in einem Zug Hauptstromrauch von Zigaretten vorgestellt. Eine rotierende Rauchmaschine mit einer DoppelfilterSchnittstelle wurde verwendet, um Zigaretten mit unterschiedlichem Menthol- und Teergehalt abzurauchen, welcher anhand der Cambridge-Filter-Methode bestimmt wurde. Die Doppelfilter-Schnittstelle dreht sich zum Auffangen des Rauchs aus jedem Zigarettenzug jeweils mechanisch auf einen neuen Filter. Die Extrakte aus jedem einzelnen Filter wurden mittels Gaschromatographie/ Massenspektrometrie (GC/MS) analysiert, um die Mentholaufnahme Zug für Zug zu bestimmen. Die Zug-für-ZugMentholprofile zeigen einen Anstieg der Mentholrauch- aufnahme mit zunehmender Zugzahl. Dieser Trend stimmte mit den Profilen für die Gesamt-Feinpartikel und die Aufnahme von anderen Bestandteilen des Hauptstromrauchs überein. Die Summe der zugeführten Mentholmengen pro einzelnem Zug ist vergleichbar mit der auf einem einzigen Filter aufgefangenen Mentholrauchzufuhr aus der gesamten Zigarette. Mit dieser Methode kann auch die quantitative Zug-für-Zug-Aufnahme von anderen Bestandteilen des Hauptstromrauchs von Zigaretten bestimmt werden. [Beitr. Tabakforsch. Int. 25 (2013) 528-534]

\section{RESUME}

Une méthode d'analyse du menthol dans une seule bouffée de fumée principale de cigarette est présentée. Une machine à fumer rotative avec interface à double filtre a été utilisée pour la fume des cigarettes, avec une variation des apports en menthol et en goudron déterminés sur la base de la méthode du filtre Cambridge. L'interface à double filtre commute mécaniquement sur un nouveau tampon-filtre qui collecte la fumée issue de chaque bouffée de cigarette. Les différents extraits de tampon-filtre ont été analysés par chromatographie en phase gazeuse-spectrométrie de masse (GC-MS) afin de déterminer les apports en menthol bouffée par bouffée. Les courbes bouffée par bouffée pour le menthol montrent une augmentation de l'apport en menthol dans la fumée en fonction du nombre croissant de bouffées, une tendance en adéquation avec les courbes d'apport total en particules et en fumée d'autres constituants de la fumée principale. La somme des apports en menthol par bouffée est comparable à l'apport total en menthol dans la fumée de cigarette telle qu'elle est collectée sur un tampon-filtre individuel. Cette méthode permet également de déterminer quantitativement les apports bouffée par bouffée d'autres constituants de la fumée principale de cigarette. [Beitr. Tabakforsch. Int. 25 (2013) 528-534] 


\section{KEY WORDS}

Menthol; cigarette smoke; puff-by-puff; total particulate matter; gas chromatography-mass spectrometry

\section{INTRODUCTION}

Menthol is a widely studied cigarette additive that contributes to the flavor and sensory attributes of mentholated cigarettes. Several factors influence menthol migration in a cigarette and its transfer to cigarette smoke, such as its point of application (tobacco, filter plug or foil), tobacco rod configuration and filter material (1). During smoking, the menthol flavor is distributed between the mainstream smoke, sidestream smoke and the filter plug (2). Mainstream smoke is defined as the smoke that emerges from the mouth end of the cigarette during puffing and is inhaled by the smoker, while the sidestream smoke is emitted from the lit end of a smoldering cigarette, through the paper or the mouth end during static burn. The potential effects of mentholated cigarettes on the smoker have been reviewed by WERLEY et al. (3). Several analytical methods have been reported for the measurement of menthol in cigarette smoke, tobacco, and filter plug $(4,5)$. The mainstream menthol cigarette deliveries are typically reported as milligrams of menthol delivered per cigarette (menthol/cig) (6). This study reports a method that measures the amount of menthol delivered per puff (menthol/puff).

A wide range of chemical compounds have been reported in cigarette smoke (7-11). Due to the complexity of cigarette smoke, most quantitative methods typically focus on fewer target compounds (12-16). Alternatively, to gain further understanding of cigarette smoke chemistry, several researchers have analyzed individual cigarette puffs to determine changes in smoke composition as the cigarette is smoked (17-26). Several cigarette smoke constituents such as nicotine, $\mathrm{CO}_{2}, \mathrm{CO}(20,21)$, acrolein, 1,3-butadiene (22), formaldehyde, tobacco-specific nitrosoamines (TSNAs), carbonyls (24), PAHs (25) and trace metals (26) have been determined in a single puff of cigarette smoke. Mathematical modeling has also been applied to simulate the cigarette burning during puffing and to predict single puff deliveries (27-29).

To determine the mainstream menthol smoke delivery of a cigarette, typically multiple cigarettes (5-20) are smoked using a linear or rotary smoking machine $(4,5)$. Menthol in smoke is collected using a 44 or $92 \mathrm{~mm}$ diameter Cambridge filter pad. The filter pad is extracted using an alcohol solution (such as ethanol or methanol) and the filtered extract is analyzed by gas chromatography. The total amount of menthol (in milligrams) measured and the number of cigarettes smoked are used to calculate an average menthol delivery per cigarette. The above procedure is applicable to menthol cigarettes with a "tar" range of $8-21 \mathrm{mg}$, following the Cambridge filter method (30).

In this study, a 20-port rotary smoking machine with a twin filter interface was used to smoke menthol cigarettes following the Cambridge filter method. The twin filter interface mechanically switches to a new filter pad and collects smoke from each cigarette puff. The individual filter pad extracts were then analyzed by gas chromatography-mass spectrometry (GC-MS) to determine the single puff menthol deliveries. This quantitative method was applied to determine the puff-by-puff menthol smoke delivery profile of menthol cigarettes. The mathematical sum of single puff menthol deliveries was compared to the whole cigarette menthol smoke delivery. The puff-by-puff profiles of menthol, total particulate matter and other mainstream smoke constituents are discussed.

\section{MATERIALS AND METHODS}

\section{Chemicals}

L-Menthol and 1-octanol (internal standard) were purchased from Fisher Scientific (Pittsburgh, PA). Ethanol (190 proof, 95\%) was obtained from Aaper Alcohol and Chemical Co. (Shelbyville, KY). Menthol calibration standards in the concentration range of $0.01-1.2 \mathrm{mg} / \mathrm{mL}$ were used to determine menthol smoke deliveries from single puff and whole cigarette analyses.

\section{Smoking procedure}

Commercially available menthol cigarettes (A, B and C) with increasing "tar" and menthol deliveries were used in this study. The design parameters of the cigarettes used are listed in Table 1. Prior to smoking, unopened packs of menthol cigarettes were conditioned to $75 \pm 2 \mathrm{~F}$ and $60 \pm 2 \%$ relative humidity for at least 24 hours. All smoking experiments were performed following the Cambridge filter method (30) of $35 \mathrm{~mL}$ puff volume, $2 \mathrm{~s}$ puff duration and $60 \mathrm{~s}$ puff interval. Puff-by-puff smoke collection was performed on a Borgwaldt RM-20 rotary smoking machine (Model - RM-20 CSR) with the twin filter interface (Figure 1) purchased from Borgwaldt K.C. Inc. (Richmond, VA). For whole cigarette analysis, cigarettes were smoked on the 20-port rotary smoking machine without the twin filter interface.

Prior to smoking, $44 \mathrm{~mm}$ diameter Cambridge filter pads purchased from Borgwaldt K.C. Inc. (Richmond, VA) were placed in filter pad holders. Initial weight of the filter pads and holders were recorded to the nearest $0.1 \mathrm{mg}$. A leak tester and soap bubble flow meter purchased from Borgwaldt K.C. Inc. (Richmond, VA) were used to set up the smoking machine to Cambridge filter method conditions. Five cigarettes were loaded onto the smoking

Table 1. Design parameters for cigarettes A, B and C with increasing menthol and "tar" deliveries.

\begin{tabular}{lrrrr}
\hline Parameter & Cig A & Cig B & \multicolumn{1}{c}{ Cig C } \\
\hline Cigarette length (mm) & 83 & 83 & 83 \\
Filter length (mm) & 27 & 27 & 21 \\
Cigarette circumference $(\mathrm{mm})$ & 24.8 & 24.8 & 24.8 \\
Total RTD (mm H $\left.\mathrm{m}_{2} \mathrm{O}\right)$ & 111 & 108 & 105 \\
Ventilation (\%) & 46 & 34 & 18 \\
"Tar" / ISO (mg/cig) & 6 & 10 & 14 \\
Puff count ISO/cig & 7.3 & 7.7 & 8.2 \\
\end{tabular}




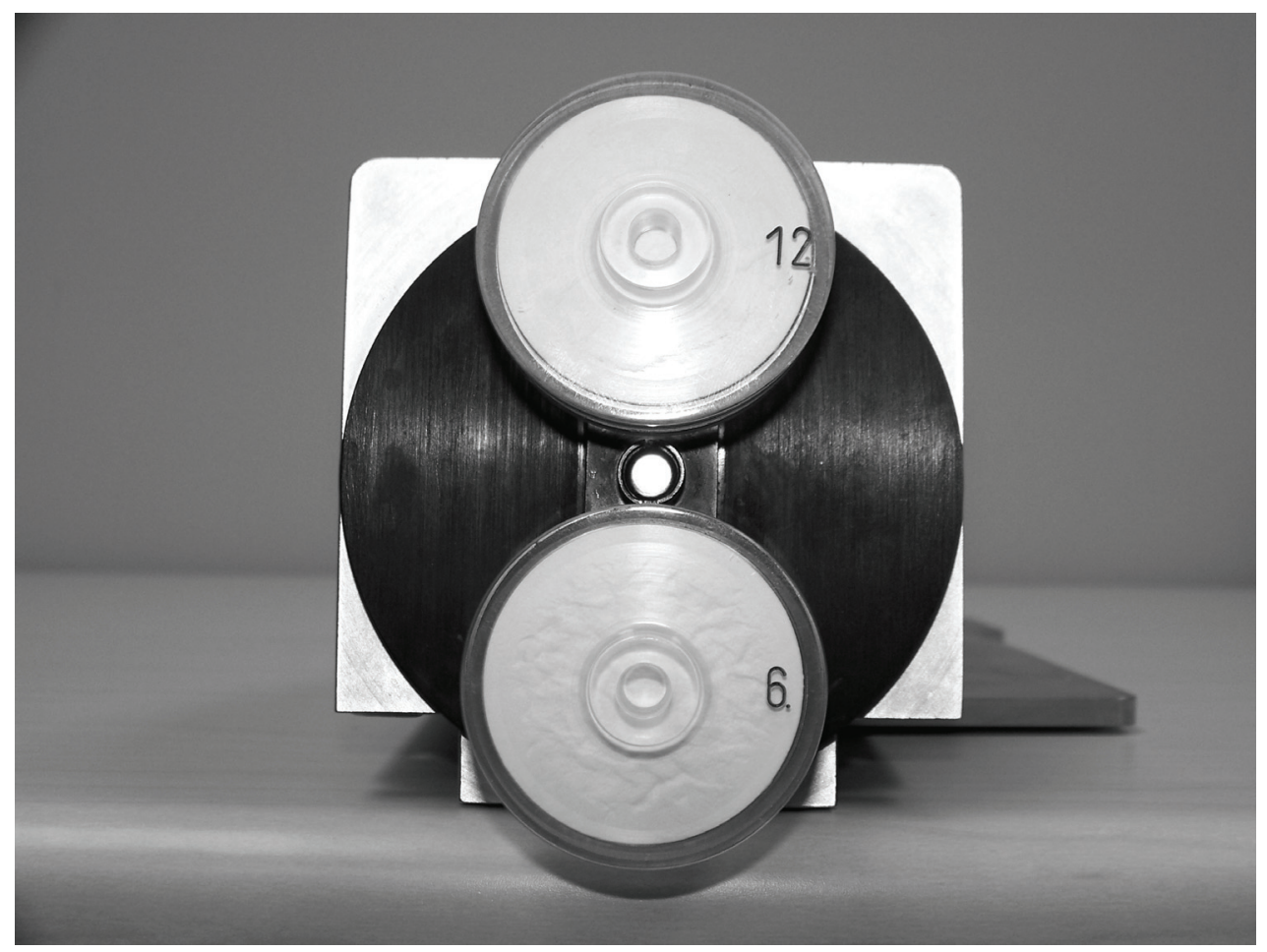

Figure 1. Photograph of the twin filter interface for Borgwaldt RM-20 smoking machine that mechanically switches the filter on and off-line for collection of smoke from each cigarette puff.

machine for both single puff and whole cigarette analyses. The cigarettes were lit using an electrical lighter purchased from Borgwaldt K.C. Inc. (Richmond, VA).

For puff-by-puff analysis, smoke from the first puff of all the five cigarettes was collected on the first filter pad. After the first puff was collected, the twin filter interface mechanically rotated, collecting the second cigarette puff on the second filter pad. The first pad holder, now off-line was switched with the third filter pad holder for collection of the third cigarette puff. Similarly, the remaining cigarette smoke puffs (puffs 4 through 9) were collected on individual filter pads. Cigarettes were smoked to the same butt length, $3 \mathrm{~mm}$ from the tipping paper, before smoking was terminated. The filter pads and holders were reweighed. The pad was removed from the holder and placed in a $25-\mathrm{mL}$ amber Erlenmeyer flask. Ten milliliters of ethanol extraction solution containing the internal standard compound (1-octanol) was added to the flask. Smoke extracts were shaken on the Orbital shaker acquired from Lab-Line Instruments, Inc. (Melrose Park, IL) at $350 \mathrm{rpm}$ (rotations per minute) for $30 \mathrm{~min}$. The smoke extracts were filtered using $5 \mathrm{~mL}$ disposable syringes from Becton-Dickinson (Franklin Lakes, NJ) containing a $0.45 \mu \mathrm{m}$ pore size disposable PVDF filter from Whatman Inc. (Florham Park, NJ). Samples were transferred to $2 \mathrm{~mL}$ autosampler vials obtained from National Scientific Company (Duluth, GA) for GC-MS analysis to determine milligrams of menthol per puff.

For whole cigarette analysis, five cigarettes were smoked for each determination of menthol smoke delivery. Menthol from mainstream cigarette smoke was trapped using a single pad holder containing a $44 \mathrm{~mm}$ diameter Cambridge filter pad. The smoked filter pads were extracted and analyzed as described above to determine milligrams of menthol per cigarette.

\section{GC-MS analysis}

An Agilent Technologies (Santa Clara, CA) 6890 gas chromatograph coupled with an Agilent 5973 quadrupole mass spectrometer was used for menthol determination. Separations were performed on an Agilent DB-WAXETR capillary column with following dimensions: $30 \mathrm{~m}$ length, $0.25 \mathrm{~mm}$ inner diameter and $0.25 \mu \mathrm{m}$ film thickness. The GC oven temperature was programmed from an initial temperature of $130{ }^{\circ} \mathrm{C}$ for $1 \mathrm{~min}$, followed by a ramp to $180{ }^{\circ} \mathrm{C}$ at $10{ }^{\circ} \mathrm{C} / \mathrm{min}$ with no hold time, followed by a second ramp to a final temperature of $260^{\circ} \mathrm{C}$ at $40{ }^{\circ} \mathrm{C} / \mathrm{min}$ with no hold time. The injection port and ion source temperatures were set at $250{ }^{\circ} \mathrm{C}$ and $230{ }^{\circ} \mathrm{C}$, respectively. Menthol smoke extracts were injected into the $\mathrm{GC}$ inlet at a 50:1 split ratio with helium carrier gas flow rate of $1.0 \mathrm{~mL} / \mathrm{min}$. Mass spectral data was collected in the scan mode with a mass range of 35-400 amu, and selected ions for menthol $(\mathrm{m} / \mathrm{z}=71)$ and 1-octanol $(\mathrm{m} / \mathrm{z}=56)$ were used for quantitation. Menthol calibration range of $0.01-1.2 \mathrm{mg} / \mathrm{mL}\left(\mathrm{R}^{2} \geq 0.999\right)$, was used to determine menthol in a single puff and whole cigarette smoke samples. The limit of detection (LOD) and the limit of quantitation (LOQ) for menthol determination in a single puff of cigarette smoke by this method are 4 and $16 \mu \mathrm{g} /$ puff, respectively.

\section{Data analysis}

The difference between the initial and final weights of the filter pad was used to determine the milligrams of total particulate matter (TPM) collected. TPM values were divided by number of cigarette smoke puffs to determine TPM/puff. Similarly, milligrams of menthol measured were divided by the number of cigarette puffs to determine men- 


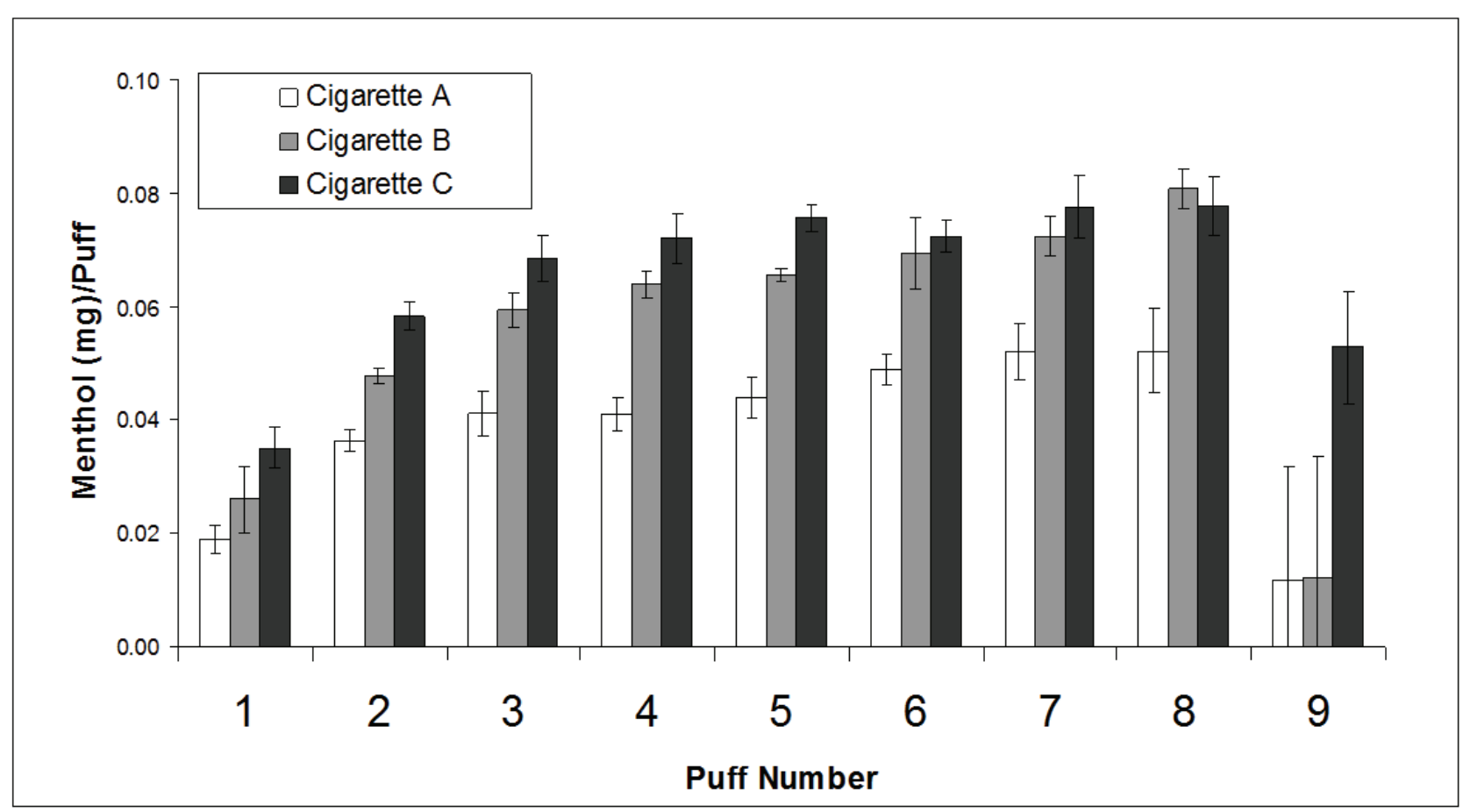

Figure 2. Puff-by-puff menthol profile $(\mathrm{N}=3)$ for cigarettes $\mathrm{A}, \mathrm{B}$ and $\mathrm{C}$ with increasing menthol and "tar" deliveries determined using Cambridge filter method. Error bars represent one standard deviation.

thol/puff. For whole cigarette delivery, milligrams of menthol measured were divided by the number of cigarettes smoked to determine menthol/cigarette.

\section{RESULTS AND DISCUSSION}

\section{Menthol puff-by-puff profile}

The amount of menthol yielded in each individual puff of mainstream cigarette smoke was determined using the Cambridge filter method for menthol cigarettes A, B and C with increasing menthol and "tar" deliveries. The puff-bypuff menthol delivery profile of all the three cigarettes studied is shown in Figure 2. The data plotted is the average of 3 independent measurements $(\mathrm{N}=3)$ and the error bars represent a single standard deviation. Each cigarette delivered at least 9 puffs, however, the $9^{\text {th }}$ puff for cigarettes $\mathrm{A}$ and $\mathrm{B}$ had lower menthol delivery when compared to the $9^{\text {th }}$ puff of cigarette C. As discussed in the smoking procedure, all the cigarettes were smoked to the same length, $3 \mathrm{~mm}$ from the tipping paper before the smoking was terminated. In the case of cigarettes A and B, the $9^{\text {th }}$ puff was a partial puff, resulting in lower menthol delivery and higher variability in the observed data.

As observed in Figure 2, the menthol delivery for the first puff, also known as the lighting puff is lower when compared to puffs 2 through 8 for all three cigarettes studied. In general, the puff-by-puff menthol delivery increases with each successive cigarette puff (puffs 1-8). A fraction of menthol from the initial puff distills and condenses on the unconsumed tobacco column and filter plug. With increasing puff count, there is a gradual reduction in tobacco rod length which decreases the filtration efficiency of the tobacco column and the filter plug as some of the distilled menthol revaporizes into cigarette smoke. The above observation for menthol puffby-puff smoke delivery profile is similar to the hypothesis stated by WAGNER et al. (24) for puff-by-puff delivery profiles for various mainstream cigarette smoke constituents.

The cellulose acetate filter plug also has a high affinity for menthol and is known to retain some of the smoke menthol (31). CURRAN and Miller (32) examined the factors influencing the elution of semi-volatile components such as menthol from the filter plug material. They indicated that the chemical composition and temperature of the aerosol and filter plug were important in controlling elution behavior. The menthol puff-by-puff profile observed in Figure 2 is consistent with the puff-by-puff delivery trends of other mainstream smoke constituents such as carbonyls, volatile organic compounds (VOCs) and TSNAs (24). WAGNER and co-workers also indicated that certain compounds in cigarette smoke have a different puff-by-puff profile, such as formaldehyde where the largest amount is delivered in the first cigarette puff (24).

\section{Comparison of puff-by-puff and whole cigarette menthol} deliveries

The whole cigarette menthol delivery was determined by trapping smoke menthol using a single filter pad. The whole cigarette menthol delivery for cigarettes $\mathrm{A}, \mathrm{B}$ and $\mathrm{C}$ was determined to be $0.32 \pm 0.01,0.56 \pm 0.01$ and $0.60 \pm 0.06 \mathrm{mg} / \mathrm{cig}$, respectively. The menthol puff-by-puff deliveries (puffs 1-9) were summed (Table 2) to mathematically determine the total puff-by-puff delivery for menthol cigarettes A, B and C: $0.35 \pm 0.05,0.50 \pm 0.05$ and $0.59 \pm 0.04 \mathrm{mg} / \mathrm{cig}$, respectively. As observed from the above data, the total puff-by-puff menthol deliveries are 
Table 2. Puff-by-puff and whole cigarette menthol deliveries for cigarettes A, B and C with increasing menthol and "tar" deliveries determined using Cambridge filter method $(\mathrm{N}=3)$.

\begin{tabular}{|c|c|c|c|}
\hline \multirow{2}{*}{ Puff number } & \multicolumn{3}{|c|}{ Menthol (mg) } \\
\hline & Cig A & Cig B & Cig C \\
\hline 1 & 0.019 & 0.026 & 0.035 \\
\hline 2 & 0.036 & 0.048 & 0.058 \\
\hline 3 & 0.041 & 0.059 & 0.069 \\
\hline 4 & 0.041 & 0.064 & 0.072 \\
\hline 5 & 0.044 & 0.066 & 0.076 \\
\hline 6 & 0.049 & 0.069 & 0.072 \\
\hline 7 & 0.052 & 0.072 & 0.078 \\
\hline 8 & 0.052 & 0.081 & 0.078 \\
\hline 9 & 0.012 & 0.012 & 0.053 \\
\hline \multicolumn{4}{|c|}{ Total puff-by-puff delivery (mg/cig) } \\
\hline & $0.35 \pm 0.05$ & $0.50 \pm 0.05$ & $0.59 \pm 0.04$ \\
\hline \multicolumn{4}{|c|}{ Whole cigarette delivery ( $\mathrm{mg} / \mathrm{cig})$} \\
\hline & $0.32 \pm 0.01$ & $0.56 \pm 0.01$ & $0.60 \pm 0.06$ \\
\hline
\end{tabular}

comparable to the whole cigarette menthol deliveries; however, additional measurements are required to establish statistical significance of these results. Single puff measurements can be quantitative; however, as the smoke collection procedure requires manual switching of filter pads during the smoking experiment, this could increase the overall method variability.

Single puff menthol deliveries were used to calculate the percentage of menthol transferred to the mainstream smoke on a per-puff-basis. The percent mainstream menthol delivered in puffs 1 through 9 for each of the three cigarettes is plotted in Figure 3. Although the absolute amount of menthol delivered per puff is different for menthol cigarettes A, B and C (Figure 2), the percent of total menthol delivered for the three cigarettes is within $\pm 3 \%$ for puffs 1 through 8 (Figure 3 ).

\section{Correlation between puff-by-puff menthol and TPM deliveries}

The puff-by-puff profile of the TPM collected for menthol cigarettes A, B and C is plotted in Figure 4. As observed from Figure 2 and Figure 4, the puff-by-puff menthol and TPM show a similar delivery profile. As a result the relationship between single puff menthol and TPM deliveries was determined. Strong correlation between the puff-bypuff menthol and TPM deliveries was observed for cigarette $A\left(R^{2}=0.95\right)$, cigarette $B\left(R^{2}=0.95\right)$ and cigarette $C$ $\left(\mathrm{R}^{2}=0.97\right)$. Similar findings were reported by COUNTS et al. (8) for strong correlation between mainstream "tar" (defined as the weight of the TPM minus the weight of nicotine and water) and most mainstream smoke constituents.

\section{CONCLUSIONS}

A method for the determination of menthol in a single puff of mainstream cigarette smoke has been developed. Menthol puff-by-puff profiles for cigarettes $\mathrm{A}, \mathrm{B}$ and $\mathrm{C}$ with increasing menthol and "tar" delivery were determined. In general, the puff-by-puff menthol delivery increases with each successive cigarette puff (puffs 1-8), a trend consis-

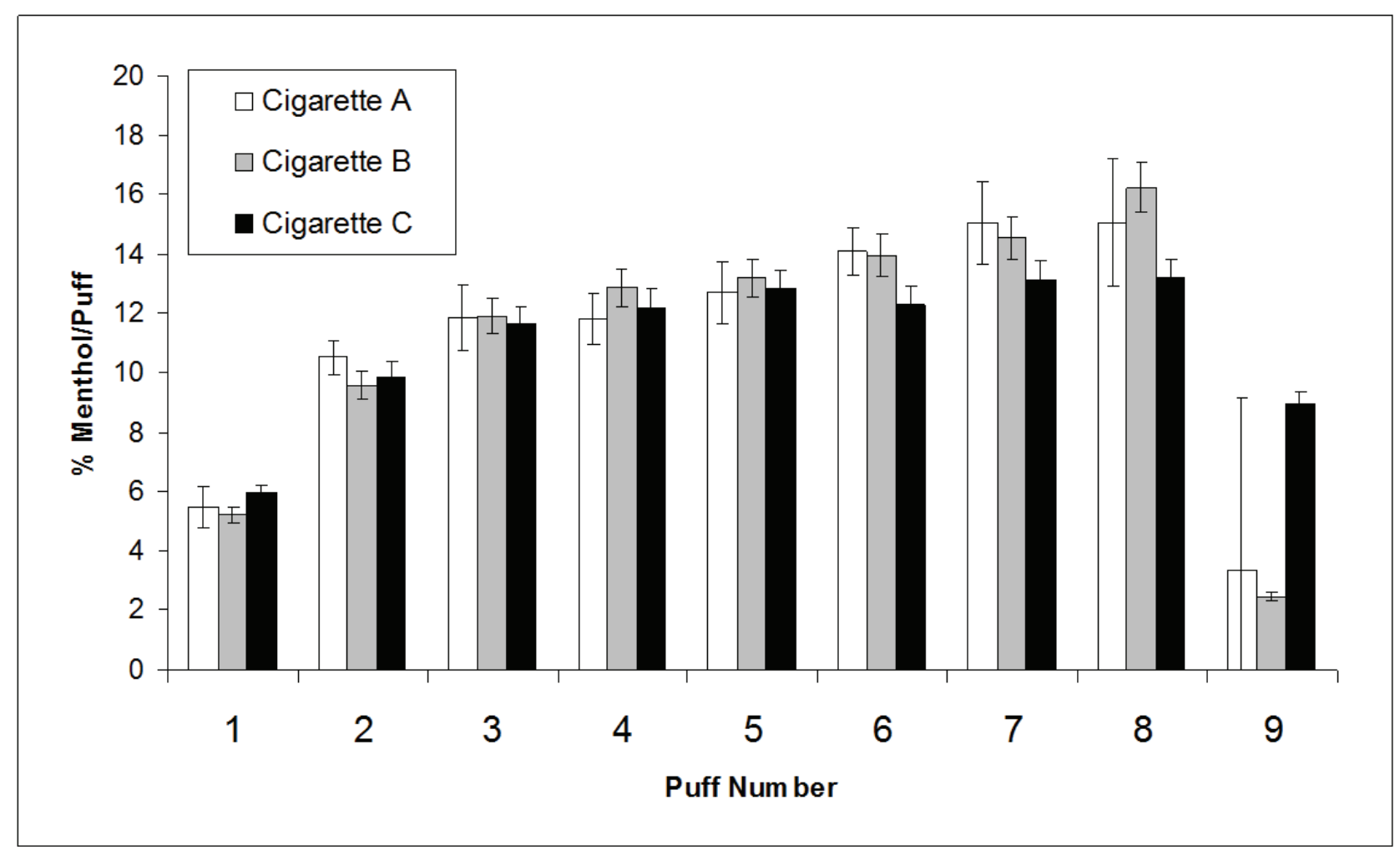

Figure 3. Percent mainstream menthol delivered per individual puff of cigarette smoke for cigarettes A, B and C with increasing menthol and "tar" deliveries determined using Cambridge filter method ( $\mathbf{N}=\mathbf{3}$ ). Error bars represent one standard deviation. 


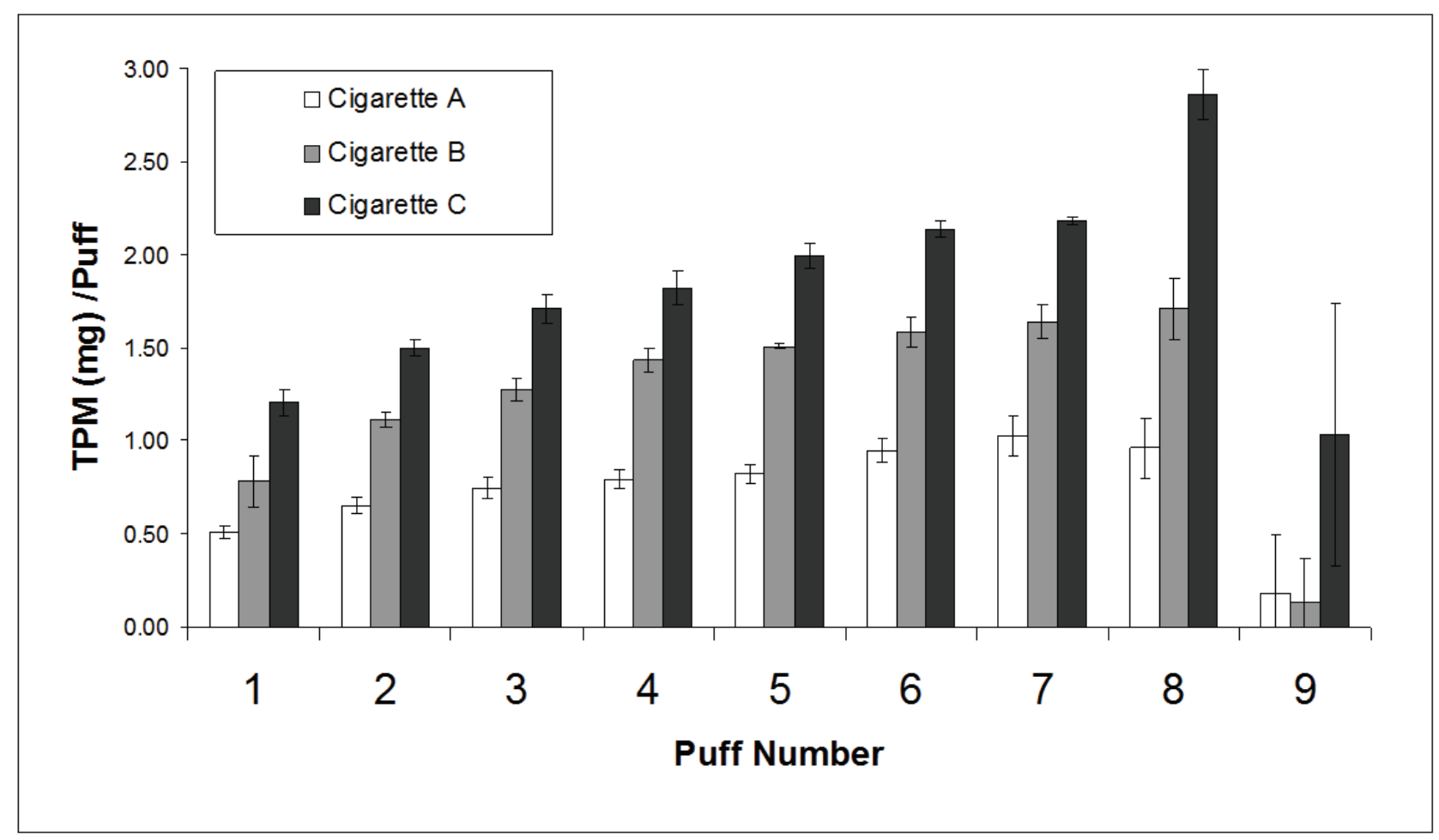

Figure 4. Puff-by-puff profile of total particulate matter (TPM, in $\mathrm{mg}$ ) for menthol cigarettes $A$, $B$ and $C$ with increasing menthol and "tar" deliveries determined using Cambridge filter method $(\mathrm{N}=3)$. Error bars represent one standard deviation.

tent with deliveries of other mainstream smoke constituents (24). The total puff-by-puff delivery, which is the mathematical sum of single puff menthol deliveries, was observed to be comparable to the experimentally determined whole cigarette menthol smoke delivery; however, additional measurements are required to establish statistical significance of these results. As the puff-by-puff analysis requires smoke collection of each individual puff on a separate filter pad, this step could result in higher method variability. The LOD and LOQ for determination of menthol in a single puff of cigarette smoke using this method are 4 and $16 \mu \mathrm{g} /$ puff, respectively. Mainstream puff-by-puff menthol and TPM deliveries strongly correlate $\left(\mathrm{R}^{2} \geq 0.95\right)$ with each other for the menthol cigarettes studied, a trend consistent with other particulate phase smoke constituents (8). This method could be applied to determine quantitative puff-by-puff deliveries of other smoke constituents such as PAHs and TSNAs that can be trapped with the Cambridge filter method.

\section{ACKNOWLEDGMENTS}

We acknowledge Ernest Lambert for his technical assistance and the technical staff at Altria Client Services for reviewing this manuscript.

\section{REFERENCES}

1. Best, F.W.: Effects of Some Cigarette Construction Parameters on Menthol Migration and Transfer. $47^{\text {th }}$ Tobacco Chemists' Research Conference, Gatlinburg,
TN, USA 1993, 155-1201.

2. Jenkins Jr, R.W., R.N. Newman, and M.K. Chavis: Cigarette Smoke Formation Studies II: Smoke Distribution and Mainstream Pyrolytic Composition of Added ${ }^{14}$ C-Menthol (U); Beitr. Tabakforsch. 1970, 5, 299-301.

3. Werley, M.S., C.R.E. Coggins, and P.N. Lee: Possible Effects on Smokers of Cigarette Mentholation: A Review of the Evidence Relating to Key Research Questions; Regul. Toxicol. Pharmacol. 47 (2007) 189-203.

4. Mitchell, B.C., E.P. Barbee, and R.M. Irby Jr: The Chromatographic Determination of Menthol in Cigarettes and Cigarette Smoke; Tob. Sci. 7 (1963) 64-66.

5. Borgerding, M.F.: The Chemical Determination of Menthol in the Tobacco Industry From An Historical Perspective; $47^{\text {th }}$ Tobacco Chemists' Research Conference, Gatlinburg, TN, USA, 1993, 85-128.

6. Curran, J.G.: Delivery of Menthol from Cigarettes Containing Either a Mentholated Filter or Mentholated Tobacco; Tob. Sci. 16 (1972) 40-42.

7. Dube, M.F. and C.R. Green: Methods of Collection of Smoke for Analytical Purposes; Rec. Adv. Tob. Sci. 8 (1982) 42-102.

8. Counts, M.E., F.S. Hsu, S.W. Laffoon, R.W. Dwyer, and R.H. Cox: Mainstream Smoke Constituent Yields and Predicting Relationships from a Worldwide Market Sample of Cigarette Brands: ISO Smoking Conditions; Regul. Toxicol. Pharmacol. 39 (2004) 111-134.

9. Swauger, J.E., T.J. Steichen, P.A. Murphy, and S. Kinsler: An Analysis of the Mainstream Smoke Chemistry of Samples of the U.S. Cigarette Market Acquired Between 1995 and 2000; Regul. Toxicol. Pharmacol. 35 (2002) 142-156. 
10. Hofmann, D.: Analysis of Toxic Smoke Constituents. A Report to the U.S. Consumer Product Safety Commission, Chapter D, 1993.

11. Dallüge, J., L.L.P. van Stee, X. Xu, J. Williams, J. Beens, R.R.J. Vreuls, and U.A.T. Brinkman: Unravelling the Composition of Very Complex Samples by Comprehensive Gas Chromatography Coupled to Timeof-flight Mass Spectrometry: Cigarette Smoke. J. Chromatogr. A. 974 (2002) 169-184.

12. Chen, P.X. and S.C. Moldoveanu: Mainstream Smoke Chemical Analyses for 2R4F Kentucky Reference Cigarette; Beitr. Tabakforsch. Int. 20 (2003) 448-458.

13. Ding, Y.S., D.L. Ashley, and C.H. Watson: Determination of 10 Carcinogenic Polycyclic Aromatic Hydrocarbons in Mainstream Cigarette Smoke; J. Agric. Food Chem. 55 (2007) 5966-5973.

14. Moldoveanu, S.C. and M. Kiser: Gas Chromatography/Mass Spectrometry Versus Liquid Chromatography/Fluorescence Detection in the Analysis of Phenols in Mainstream Cigarette Smoke; J. Chromatogr. A 1141 (2007) 90-97.

15. Lu, X., J. Cai, H. Kong, M. Wu, R. Hua, M. Zhao, J. Liu, and G. Xu: Chromatography/time-of-flight Mass Spectrometry. I: Acidic Fraction; Anal. Chem. 75 (2003) 4441-4451.

16. Lu, X., M. Zhao, H. Kong, J. Cai, J. Wu, M. Wu, R. Hua, J. Liu, and G. Xu: Characterization of Cigarette Smoke Condensates by Comprehensive Two-dimensional Gas Chromatography/time-of-flight Mass Spectrometry (GCxGC/TOF-MS) Part 2: Basic Fraction; J. Sep. Sci. 27 (2004) 101-109.

17. Bush, L.P., C. Grunwald, and D.L. Davis: Influence of Puff Frequency and Puff Volume on the Alkaloid Content of Smoke; J. Agric. Food Chem. 20 (1972) 676-678.

18. Ceschini, P. and A. Lafaye: Evolution of the GasVapour Phase and the Total Particulate Matter of Cigarette Smoke in A Single Puff; Beitr. Tabakforsch. 8 (1976) 378-381.

19. Thomas, C.E. and K.B. Koller: Puff-by-puff Mainstream Smoke Analysis by Multiplex Gas Chromatography-Mass Spectrometry; Beitr. Tabakforsch. Int. 19 (2001) 345-351.

20. Adam, T., R.R. Baker, and R. Zimmermann: Characterization of Puff-by-puff Resolved Cigarette Mainstream Smoke by Single Photon Ionization - Time-of-flight Mass Spectrometry and Principal Component Analysis; J. Agric Food Chem. 55 (2007) 2055-2061.

21. Crawford, D.R., M.E. Parrish, D.L. Gee, and C.N. Harward: Intra-puff $\mathrm{CO}$ and $\mathrm{CO}_{2}$ Measurements of Cigarettes with Iron Oxide Cigarette Paper Using Quantum Cascade Laser Spectroscopy; Spectrochim. Acta Part A 67 (2007) 4-15.

22. Thweatt, W.D., C.N. Harward, and M.E. Parrish: Measurement of Acrolein and 1,3-Butadiene in a Single Puff of Cigarette Smoke Using Lead-Salt Tunable Diode Laser Infrared Spectroscopy; Spectrochim. Acta Part A 67 (2007) 16-24.
23. Parrish, M.E., J.L. Lyons-Hart, and K.H. Shafer: Puffby-puff and Intrapuff Analysis of Cigarette Smoke Using Infrared Spectroscopy; Vib. Spectrosc. 27 (2001) 29-42.

24. Wagner, K.A., R. Higby, and K. Stutt: Puff-by-puff Analysis of Selected Mainstream Smoke Constituents in the Kentucky Reference 2R4F Cigarette; Beitr. Tabakforsch. Int. 21 (2005) 273-279.

25. Li, S., R.M. Olegario, J.L. Banyasz, and K.H. Shafer: Gas Chromatography-Mass Spectrometry Analysis of Polycyclic Aromatic Hydrocarbons in Single Puff of Cigarette Smoke; J. Anal. Appl. Pyrolysis 66 (2003) 155-163.

26. Chang, M.J., J.D. Naworal, and C.T. Connell: Direct Introduction of Cigarette Smoke for Puff-by-puff Trace Metals Analysis by Inductively Coupled Plasma Mass Spectrometry; J. Anal. At. Spectrom. 21 (2006) 574-581.

27. Chen, P. and R.W. Dwyer: A Puff-by-puff Delivery Model for Cigarettes; Beitr. Tabakforsch. Int. 20 (2002) 273-277.

28. Saidi, M.S., A. Mhaisekar, M.R. Hajaligol, and M. Subbiah: Mathematical Modeling of a Lit-End Cigarette: Puffing Cycle and Effects of Puff Counts; Beitr. Tabakforsch. Int. 23 (2008) 46-62.

29. Saidi, M.S., M.R. Hajaligol, and F. Rasouli: An Experimental and Numerical Analysis of Puff Hydrodynamics; Beitr. Tabakforsch. Int. 21 (2004) 157-166.

30. Counts, M.E., M.J. Morton, S.W. Laffoon, R.H. Cox, and P.J. Lipowicz: Smoke Composition and Predicting Relationships for International Commercial Cigarettes Smoked with Three Machine-Smoking Conditions; Regul. Toxicol. Pharmacol. 41 (2005) 185-227.

31. Brozinski, M., U. Dölberg, and G. Lipp: Untersuchungen über die Verteilung des Menthols aufTabak, Filter und Rauch von Mentholcigaretten [Investigations on the Distribution of Menthol in Tobacco, Filter and Smoke From Mentholated Cigarettes]; Beitr. Tabakforsch. 6 (1972) 124-130.

32. Curran Jr, J.G. and E.G. Miller Jr: Factors Influencing the Elution of High-Boiling Components of Cigarette Smoke from Filters; Beitr. Tabakforsch. 5 (1969) 64-70.

\section{Corresponding author:}

Narendra K. Meruva

Altria Client Services

Research Development \& Engineering

601 E. Jackson Street

Richmond, VA-23219

USA

E-mail: Narendra.K.Meruva@altria.com 